\title{
Article
}

\section{Crossed characterisation of polymer- layered silicate (PLS) nanocomposite morphology: TEM, X-ray diffraction, rheology and solid-state nuclear magnetic resonance measurements}

SAMYN, F, BOURBIGOT, S, JAMA, C, BELLAYER, S, NAZARE, S, Hull, T Richard, CASTROVINCI, A, FINA, A and CAMINO, G

Available at http://clok.uclan.ac.uk/1134/

SAMYN, F, BOURBIGOT, S, JAMA, C, BELLAYER, S, NAZARE, S, Hull, T Richard ORCID: 0000-0002-7970-4208, CASTROVINCI, A, FINA, A and CAMINO, G (2008) Crossed characterisation of polymer-layered silicate (PLS) nanocomposite morphology: TEM, X-ray diffraction, rheology and solid-state nuclear magnetic resonance measurements. European Polymer Journal, 44 (6). pp. 1642-1653. ISSN 00143057

It is advisable to refer to the publisher's version if you intend to cite from the work. http://dx.doi.org/10.1016/j.eurpolymj.2008.03.021

For more information about UCLan's research in this area go to http://www.uclan.ac.uk/researchgroups/ and search for <name of research Group>.

For information about Research generally at UCLan please go to http://www.uclan.ac.uk/research/

All outputs in CLoK are protected by Intellectual Property Rights law, including Copyright law. Copyright, IPR and Moral Rights for the works on this site are retained by the individual authors and/or other copyright owners. Terms and conditions for use of this material are defined in the policies page. 


\title{
Crossed characterisation of polymer-layered silicate (PLS) nanocomposite morphology: TEM, X-Ray Diffraction, Rheology and solid-state Nuclear Magnetic Resonance measurements
}

\author{
F. Samyn, ${ }^{1}$ S. Bourbigot, ${ }^{* 1}$ C. Jama, ${ }^{1}$ S. Bellayer, ${ }^{1}$ S.i Nazare, ${ }^{2}$ R. Hull, ${ }^{2}$, A. Castrovinci, ${ }^{3}$ A. \\ Fina $^{3}$ G. Camino ${ }^{3}$ \\ ${ }^{1}$ LSPES, Procédés d'Elaboration de Revêtements Fonctionnels, UMR/CNRS 8008, ENSCL, \\ BP 90108, 59652 Villeneuve d'Ascq (France) \\ ${ }^{2}$ Centre for Materials Research and Innovation, Bolton University, Deane Campus, Bolton, \\ BL3 5AB (England) \\ ${ }^{3}$ Centro Ingegneria Materie Plastiche, V.le Teresa Michel, 5, 15100 Alessandria (Italy)
}

Corresponding author: serge.bourbigot@ensc-lille.fr, tel: 03204348 88, fax: 0320436584 


\begin{abstract}
:
As the nanocomposite properties dramatically depend on the dispersion state of the filler in the matrix, it is essential to develop technical methods to characterise the nanodispersion both qualitatively and quantitatively. In this study, complete characterisations of the nanodispersion of organomodified clays in polyamide 6, polypropylene and poly(butylene terephtalate) are presented and discussed using different analytical tools including X-ray diffraction and transmission electron spectroscopy and more original and quantitative measurements like rheology and solid state NMR measurements.
\end{abstract}

Key words: Nanocomposite, dispersion, X-ray diffraction, TEM, solid state NMR, Rheology, 


\section{Introduction}

Polypropylene, polyamide 6 and poly(butylene terephtalate) are three thermoplastics of the greatest interest on an industrial point of view and this for different reasons. With around $18 \%$ of the world plastic consumption, polypropylene is one of the most used commodity polymers representing a huge market. As engineering polymers, polyamide 6 and poly(butylene terephtalate) only represents few percents of the global polymer consumption but their high added value constitutes the driving force promoting their industrial development.

With the emergence of the nanotechnology, these polymers have widened their respective application fields. Indeed, the use of nanoparticules in polymer is an effective way to improve some properties such as mechanical ${ }^{\mathbf{1 , 2 , 3 , 4}}$, barrier $^{\mathbf{5}, \mathbf{6}}$, thermal $^{7}$ and in some cases fire ${ }^{8,9}$ properties.

Among the different nanoparticules that have proved their efficiency, lamellar nanoclays and particularly montmorillonite (MMT) have a leading position. This is probably due to the large range of organomodified MMT commercially available as well as their moderated cost compared with other still expansive particles such as POSS and carbon nanotubes. In our study, we will focus on silicate layered nanocomposites.

If lamellar clay nanocomposites exhibit good properties, their achievement is closely linked to the quality of dispersion of the nanoparticles in the polymer. Two difficulties appear at the preparation stage: the control of processing conditions in order to reach nanodispersion and how to accurately characterise the dispersion state achieved.

Different synthesis pathways have been envisaged to synthesize a nanocomposite: intercalation of polymer or prepolymer from solution, in situ intercalative polymerisation or melt intercalation. Industrially the melt intercalation also named melt blending appears to be the more appealing method: it is the more rapid way to produce nanocomposites, it does not use solvent, and contrary to the other synthesis routes it enables a continuous processing. This pathway is so industrially favoured and has been used in this study. However it is to notice that in such processing, the conditions used play a very important role ${ }^{10}$. The nature of the clay, the organic cation selected as surfactant to compatibilize the clay with the matrix ${ }^{11}$, the characteristics of the polymer such as the molecular weight ${ }^{12}$ strongly affect the dispersion of the clay. 
Depending on all these factors, three main morphologies of polymer-layered silicate composite will be encountered (Figure 1). When the nanofillers have very few affinities with the polymer, the platelets remain in their initial organisation creating microparticles into the polymeric matrix. Then by increasing the compatibility between the two phases, it is possible to obtain nanocomposite morphologies. Intercalated structure will designate structure in which some polymer chains are inserted into the platelets but it still remains in general in an organisation gathering several platelets. In the ideal case, all the platelets are completely separated the ones from the others. This last case describes the delaminated or exfoliated morphology. In the majority of the polymer nanocomposites formed, a combination of delamination and intercalation is obtained.

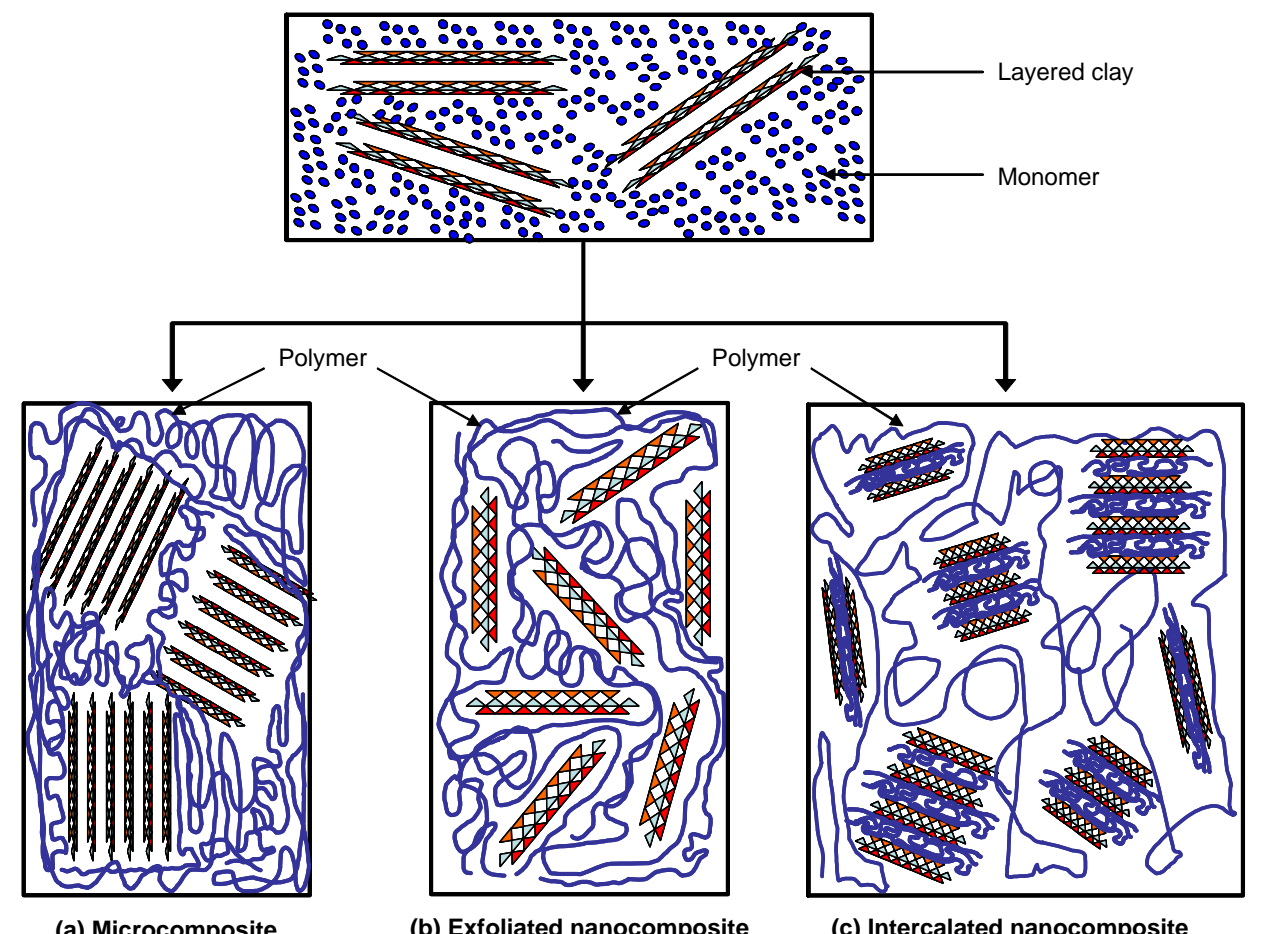

Figure 1 : Illustration of the microcomposite morphology (a) and of exfoliated (b) and intercalated (c) nanocomposites. In this scheme, the nanocomposite is prepared by polymerisation from the monomer and the organo-modified layered silicate (the proportion of clay is exaggerated for representation reasons)

One important issue when a clay polymer composite is formed, is then to characterise the dispersion obtained. The literature describes characterisation of the morphology using a lot of different techniques. If Transmission Electron Microscopy (TEM) and X-Ray Diffraction (XRD) are among the most widely used, methods such as melt Rheology, solidstate NMR, Fourier Transformed-Infrared (FT-IR), small-angle neutron scattering (SANS), ultra-small-angle neutron scattering (USANS), small-angle X-ray scattering (SAXS), and high-resolution transmission electron microscopy (HR-TEM), atomic force microscopy 
(AFM) are also mentioned. Each method possesses its advantages and drawbacks and provides a specific piece of information about the dispersion. With such a variety of tools available, which of these techniques have to be used to obtain the more complete and accurate description of the dispersion?

The purpose of this paper is to give some keys to choose the most appropriate technique of characterisation. That is the reason why, the first part of this paper is devoted to a critical overview of the different characterisation methods based on the published literature. Then XRD, TEM, melt rheology and NMR measurements will be applied concomitantly to evaluate the dispersion achieved in PA6, PBT and PP organo-clay composites prepared by direct melt blending. A discussion about the results obtained from each techniques will follow this complete characterisation to finally lead to some recommendations on how to accurately characterise nanocomposite.

\section{Methods for characterising nanodispersion}

This first part is dedicated to a critical overview of the existing characterising methods described in the nanocomposite literature. The aim of this part is not to give an exhaustive list of all available methods, but only to describe some of them and to expose their limitations.

\section{Imaging method}

TEM is classically used to analyse qualitatively the dispersion of polymer layered silicate nanocomposites (PLSN). However image analysis procedure can be used to quantify the

dispersion from TEM pictures. Vermogen et $a l^{13}$ deduce different parameters which give detailed information and allow a very fine description of the microstructure (Figure 2). The average thicknesses, lengths, and aspect ratios of each class of tactoids could be measured as well as their relative proportions and the average distances between two adjacent tactoids. 


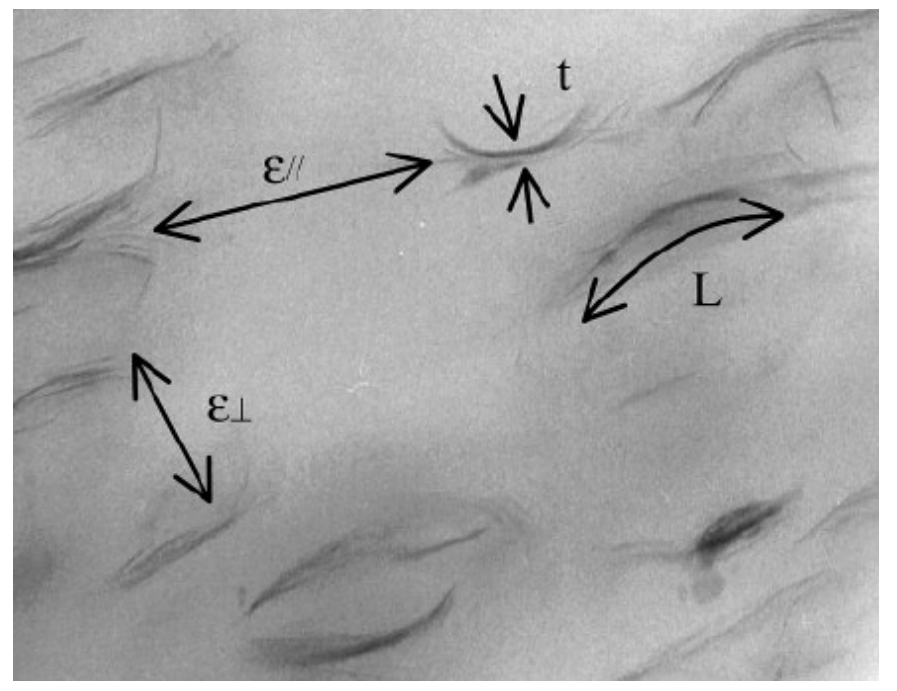

Figure 2. TEM picture of PP-PPgMA-MMT. The image shows the collected data processing image analysis: the particle curved length $(\mathrm{L})$, thickness $(\mathrm{t})$, and the interparticular distance in the direction parallel to that of the lengths of the tactoids $(\varepsilon / /)$ and perpendicular to the latter orientation $\left(\varepsilon_{\perp}\right)($ from [13])

A main disadvantage of the imaging methods is that a large number of pictures are necessary to obtain a statistical representative view of the whole sample. Moreover the procedure used to quantify the dispersion constitutes a heavy image analysis.

\section{X-Ray techniques}

X-Ray diffraction allows the measure of the interplatelets distance (d) in intercalated structures using the Bragg's law:

$$
\sin (\theta)=\frac{n \lambda}{2 d}
$$

where $\theta$ is the incident angle, $\mathrm{n}$ the integer and $\lambda$ the wavelength of the incident X-Ray beam. The observation of the changes in the diffraction angle corresponding to the plan $\mathrm{d}_{001}$ of the clay enables to characterise the dispersion. The more polymer chains are intercalated between the platelets, the more the layer distance $d$ increases and so the more the diffraction angle $\theta$ decreases. For exfoliated samples, there is no more layer structure what causes no more observation of diffraction for the $\mathrm{d}_{001}$ (Table 1). 
Table 1 : Evolution of the interlayer distance (d) according the composite morphology

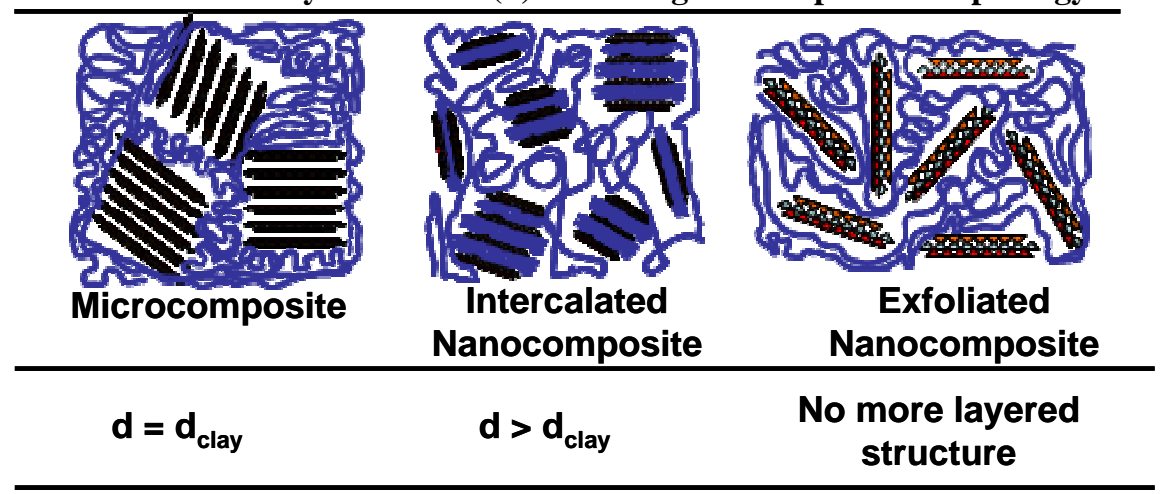

Misinterpretation of XRD data can be easily done. Some studies have demonstrated the

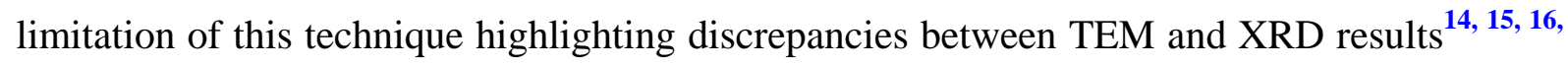
17, 18 . Clay dilution, preferred orientation, peak broadening, and mixed-layered morphology are factors that complicate the interpretation of the XRD patterns. When mixed structures of composite are obtained, the basal reflexions observed does not conform the Bragg law and so there are uncertainties about the interlayer distance measured. Clay dilution as well as parameters that can induced peak broadening can lead to the disappearance of diffraction peak resulting in the false conclusion that exfoliation has occurred. On contrary, preferred orientation effects can make think that exfoliation has not occurred. In conclusion when no peak is detected it can not be directly attributed to a complete exfoliation of the clay platelets into the polymer matrix. A disorganisation of the clay structure will also results in the disappearance of the peak even if the delamination is not achieved. That is the reason why in general, XRD analysis is not used alone in studies to deduce the nanocomposite morphology. TEM and XRD are often coupled to ensure the conclusion done from the separated analysis.

Small-angle X-ray scattering (SAXS) can be used to characterize changes in the gallery height of the clay and monitor the morphology formation in the polymer layered silicate nanocomposites. SAXS data are can be presented in terms of intensity, I, as a function of $q$, the magnitude of the scattering vector. $\mathrm{q}$ is given by the relation:

$$
q=\frac{4 \pi}{\lambda} \sin (\theta)
$$

where the scattering angle is $2 \theta$ and $\lambda$ is the wavelength of the radiation.

The length scale, $d$, corresponding to a given value of $q$ is given by the following equation:

$$
d=\frac{2 \pi}{q}
$$


and the associated gallery height, $\mathrm{h}$, is given by:

$$
\mathrm{h}=(\mathrm{d}-10) \AA .
$$

In this characterising method, two different phenomena can be observed: a reduction of the scattering intensity and a shift of the scattering maxima. They can be interpreted as follows: the reduction of the scattering intensity indicates that the clay structure becomes quite exfoliated by the polymer chains and the shift of the scattering maxima to lower q values suggests that intercalation occurs. SAXS presents the same drawbacks than XRD, that is to say when no peak is observed no conclusion can be made and other technique need to be used.

\section{Melt rheology:}

Melt rheology has been discussed at length as a method to characterise polymer-clay nanocomposites ${ }^{19}, 20,21$. Pronounced shear thinning has been found to be a characteristic feature of truly nanodispersed composites. Incarnato et $\mathrm{al}^{22}$ studied rheological behaviour of polyamide-based nanocomposites and related their results to TEM observations. Their results showed evidence that the flow curve shape of the nanocomposites is associated with the exfoliation and intercalation level of the silicate platelets in the polymer matrix. Samples whose complex viscosity curve shows marked shear thinning, show more uniform dispersion of clay particles on micron as well as nanoscale. Hybrids showing complex viscosity curves with moderate deviations from pseudo-Newtonian trend show micron-scale morphology comprised of intercalated aggregates.

Wagener and Reisinger ${ }^{23}$ have developed a method to quantify shear thinning of polymer-clay nanocomposites and used the shear thinning exponent $n$ to compare the extent of delamination of platelets. This parameter is obtained from the flow curves by fitting to the power law expression:

$$
\eta=A \omega^{n}
$$

where $A$ is a sample specific pre-exponential factor, $\eta$ the apparent viscosity, $\omega$ the shear rate and $\mathrm{n}$ the shear thinning coefficient. They concluded that the shear thinning exponent $n$ is a semi-quantitative measure of the degree of exfoliation and delamination. However, there is no obvious relation between the shear thinning exponent $n$ and the degree of delamination. The average number of nanoplatelets per tactoid for a given nanocomposite cannot be calculated from $n$. 


\section{Solid state NMR:}

The NMR methodology to assess the nanodispersion degree has been developed at the National Institute of Standards and Technology by VanderHart et al. ${ }^{24,25}$. It is based on proton longitudinal relaxation time $\left(\mathrm{T}_{1}{ }^{\mathrm{H}}\right)$ measurements. The $\mathrm{T}_{1}{ }^{\mathrm{H}}$ value is affected by the presence of clay. The structure of a clay platelet is based one octahedral alumina layer surrounded by two tetrahedral silicate layers. Some substitutions of octahedral $\mathrm{Al}^{3+}$ can occur in favour of $\mathrm{Mg}^{2+}$ (non stoechiometric substitutions) or $\mathrm{Fe}^{3+}$ (stoechiometric substitutions) which is paramagnetic $(S=5 / 2)$. The paramagnetism of this cation induced the formation of relaxation sinks at the surface of the clay platelets. This causes a modification of the relaxation of the polymer protons directly located at the interface polymer/platelets. Then the phenomenon of spin diffusion propagates the increase of spin relaxation to the distant protons. According to the level of dispersion, the number of relaxation sinks differs. The more the platelets are exfoliated the more relaxation sinks are created consequently the more the $\mathrm{T}_{1}{ }^{\mathrm{H}}$ decreases. The NMR method presents the advantage to directly correlate the dispersion degree with the $\mathrm{T}_{1}{ }^{\mathrm{H}}$ values measured. The calculation method is based on the resolution of the differential equations describing the phenomenon of spin diffusion. The method has been developed by Bourbigot et al. on polystyrene nanocomposites ${ }^{26}$. The model of calculation enables to quantify both the degree of separation of the platelets (factor $f$ ) and the homogeneity of the dispersion (factor e). Both factors are relative values, a perfectly well exfoliated samples is taken as reference. The relation between the factor values and the morphology of nanocomposite can be summarized as presented in Figure 3.

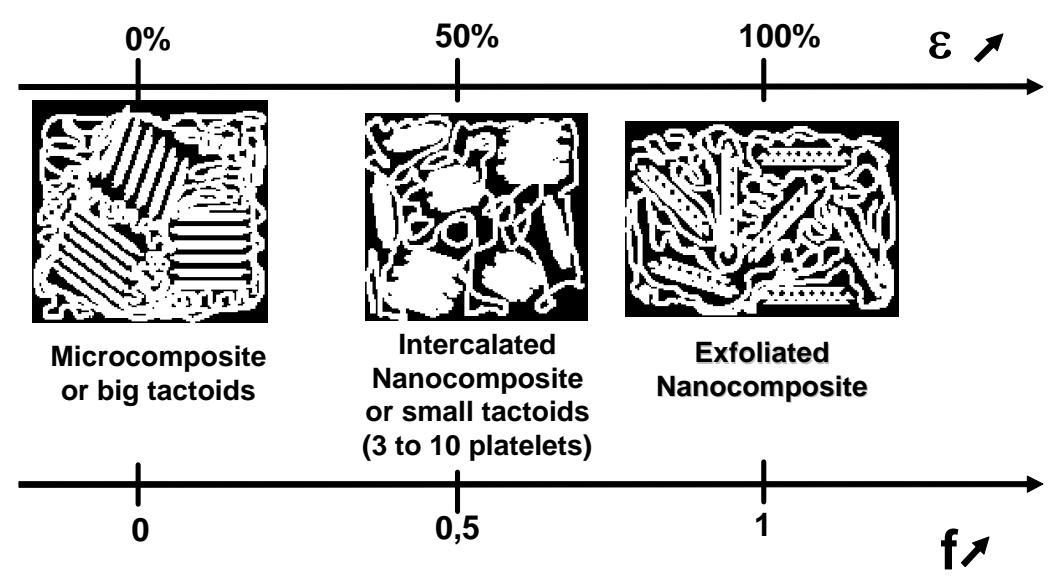

Figure 3 : relation morphology / NMR factors 


\section{Other methods:}

Sophisticated combination of techniques can be used to characterize the nanodispersion state. In a recent work $^{27}$, the dispersed microstructure of the clays in the nanocomposites was characterized by small-angle neutron scattering (SANS), ultra-small-angle neutron scattering (USANS), small-angle X-ray scattering (SAXS), and high-resolution transmission electron microscopy (HR-TEM). The mean number of individual clay platelets per tactoid was predicted by fitting SANS data to the stacked-disk model and measured directly from HRTEM images of a large number of tactoids in each sample. SAXS peaks were not present for most of the synthesized nanocomposites, suggesting a high degree of clay delamination was achieved. The HR-TEM measured distributions of clay platelet d-spacings in tactoids dispersed within the nanocomposites (Figure 4).

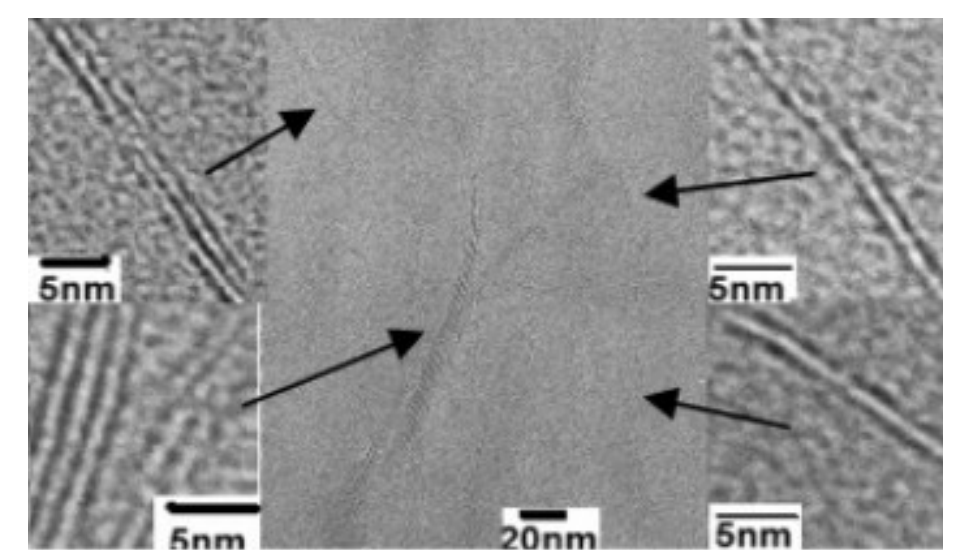

Figure 4. HR-TEM picture of highly delaminated clay/poly(dicyclopentadiene) nanocomposites (from 24)

This overview has highlighted the specificity of the techniques and their limitations. TEM and XRD have to be used carefully. TEM which enables to have a visual appreciation of the dispersion has to be performed on numerous samples to ensure the representativeness of the observation. Imaging analyses can be done on the pictures to quantify the dispersion but the method is time consuming. XRD and SAXS are very useful when intercalated structures are obtained but the interpretation of the absence of peak can be ambiguous. Melt rheology has the advantage to be a semi-quantitative method enabling to compare the dispersion of different samples. Solid state NMR has the advantage of being a quantitative method. The measurements are easy and quite rapid. 


\section{Experimental}

\subsection{Materials}

Table 2 summarizes the materials used in this work as well as the suppliers of the products and the chemical formula.

Table 2 : materials

\begin{tabular}{|c|c|c|c|c|}
\hline Product & Abbreviation & Supplier & Reference & Formula \\
\hline Polyamide 6 & PA6 & Rhodia & $\begin{array}{l}\text { Technyl } \\
\text { S27 }\end{array}$ & \\
\hline Polypropylene & PP & Basell & $\begin{array}{l}\text { Molpen } \\
\text { HO500N }\end{array}$ & \\
\hline $\begin{array}{c}\text { Polypropylene } \\
\text { grafted maleic } \\
\text { anhydride }\end{array}$ & Polybond & Crompton & $\begin{array}{c}\text { Polybond } \\
3200\end{array}$ & \\
\hline $\begin{array}{l}\text { Poly(butylene } \\
\text { terephtalate) }\end{array}$ & PBT & Ticona & $\begin{array}{l}\text { Celanex } \\
2000-2 \\
\text { natural }\end{array}$ & \\
\hline
\end{tabular}

Organomodifier

\begin{tabular}{|c|c|c|c|c|}
\hline $\begin{array}{c}\text { Cloisite 30B } \\
\text { (organomodified }\end{array}$ & $\mathrm{C} 30 \mathrm{~B}$ & $\begin{array}{c}\text { Southern } \\
\text { Clay }\end{array}$ & Cloisite & $\begin{array}{l}\mathrm{CH}_{2} \mathrm{CH}_{2} \mathrm{OH} \\
\mathrm{I}_{3} \mathrm{C}-\mathrm{N}^{+}-\mathrm{T} \\
1 \\
\mathrm{CH}_{2} \mathrm{CH}_{2} \mathrm{OH}\end{array}$ \\
\hline montmorillonite) & & Products & & Montmorillonite \\
\hline \multirow{2}{*}{$\begin{array}{c}\text { Cloisite 20A } \\
\text { (organomodified } \\
\text { montmorillonite) }\end{array}$} & \multirow{2}{*}{ C20A } & Southern & Cloisite & \\
\hline & & Products & $20 \mathrm{~A}$ & $\begin{array}{l}\text { Organomodifier } \\
\qquad \begin{array}{r}\mathrm{CH}_{3} \\
\mathrm{I}_{3}^{+}-\mathrm{N}^{+}-\mathrm{HT} \\
1 \\
\mathrm{HT}\end{array}\end{array}$ \\
\hline
\end{tabular}




\subsection{Sample preparation}

The materials (Table 3) were prepared by melt blending using an American Leistritz Extruder Model ZSE 27. This extruder has a $27 \mathrm{~mm}$ co-rotating intermeshing twin screw with 10 zones and a length/diameter ratio of 40 . The extruder design and the temperature profile are given in Figure 5 and Table 4 . The polymer pellets were introduced in the first zone and the nanofiller in the third zones with a side gravimetric feeder (screw speed $180 \mathrm{rpm}$ ). For all the formulations, both the polymer and the nanocomposite materials were prepared using this device with a screw speed of $200 \mathrm{rpm}$ and a feed rate of $10 \mathrm{~kg} / \mathrm{h}$. The material obtained is then pelletized.

Table 3 : Formulations prepared

\begin{tabular}{|c|c|c|}
\hline Formulations & Polymer (wt.-\%) & $\begin{array}{c}\text { Nanocomposite (wt.-\%) } \\
\text { (OM-MMT amounts) }\end{array}$ \\
\hline PA6 & 100 & 95 \\
\hline C30B & & 5 \\
\hline PBT & 100 & 95 \\
\hline C30B & & 5 \\
\hline \hline PP & 93.3 & 88.3 \\
\hline Polybond & 6.7 & 6.7 \\
\hline C20A & & 5 \\
\hline
\end{tabular}

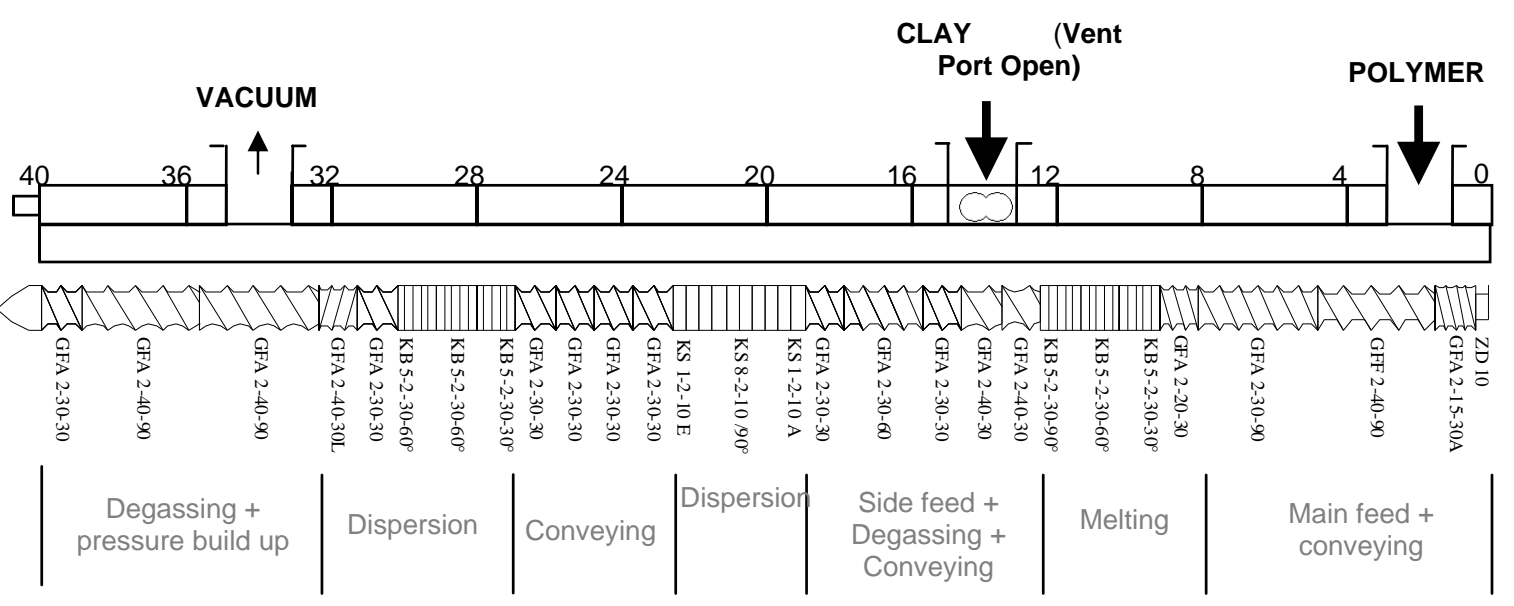

Figure 5: Screw design 
Table 4 : temperature profile for the three types of formulations

\begin{tabular}{|c|c|c|c|c|c|c|c|c|c|c|}
\hline & Zone 10 & Zone 9 & Zone 8 & Zone 7 & Zone 6 & Zone 5 & Zone 4 & Zone 3 & Zone 2 & Zone 1 \\
\hline & $36-40 \mathrm{D}$ & $32-36 \mathrm{D}$ & $28-32 \mathrm{D}$ & $24-28 \mathrm{D}$ & $20-24 \mathrm{D}$ & $16-20 \mathrm{D}$ & $12-16 \mathrm{D}$ & $8-12 D$ & $4-8 \mathrm{D}$ & $0-4 \mathrm{D}$ \\
\hline PA6 & 250 & 250 & 250 & 245 & 245 & 245 & 240 & 240 & 240 & 250 \\
\hline PBT & 255 & 255 & 255 & 245 & 245 & 245 & 240 & 240 & 240 & 250 \\
\hline PP & 230 & 230 & 230 & 220 & 220 & 220 & 210 & 210 & 210 & 220 \\
\hline
\end{tabular}

\subsection{Characterisation}

\subsubsection{Transmission Electron spectroscopy}

All samples were ultra microtomed with a diamond knife on a Leica ultracut UCT microtome, at room temperature for PP, PBT samples and at cryo temperature $\left(-120^{\circ} \mathrm{C}\right)$ for PA6 samples, to give sections with a nominal thickness of $70 \mathrm{~nm}$. Sections were transferred to $\mathrm{Cu}$ grids of 400 meshes. Bright-field TEM images of nanocomposites were obtained at $300 \mathrm{kV}$ under low dose conditions with a Philips CM30 electron microscope, using a Gatan CCD camera. Low magnification images were taken at $17000 \mathrm{x}$ and high-magnification images were taken at 100 000x.

The materials were sampled by taking several images of various magnifications over 2-3 sections per grid to ensure that analysis was based on a representative region of the sample.

EDX microanalysis were performed with a FEI Tecnai G2 20 transmission electron microscope at $200 \mathrm{kV}$.

\subsubsection{X-ray diffraction (XRD)}

XRD analyses were conducted at ambient temperature using a Philips X'Pert X-ray diffractometer $\left(\left(\lambda\left(\mathrm{Cu}_{\mathrm{K} \alpha}\right)=1.540562 \AA\right)\right.$ in configuration 2-theta/ theta on slabs of materials. XRD spectra were recorded in the $1.5^{\circ}-10^{\circ} 2 \theta$ range with a step of $0.02^{\circ}$, a step time of $2.5 \mathrm{~s}$. The interlayer spacing $\mathrm{d}$ was deduced from the recorded data.

\subsubsection{Rheology}

Rheological measurements were carried out at Dynamic Analyser Rheometer RDA II from Rheometrics. Parallel plate geometry with a plate diameter of $25 \mathrm{~mm}$ was used. Thin films of materials of $1 \mathrm{~mm}$ thickness were used to perform the tests. To ensure the viscoelastic region, linear rheological measurements were performed at a frequency range of 0.1 to $100 \%$. Elastic 
complex viscosities $\left(\eta^{*}\right)$ was obtained at $240^{\circ} \mathrm{C}$. The temperature control was accurate to within $\pm 1{ }^{\circ} \mathrm{C}$. Experiments were conducted under a nitrogen atmosphere in order to avoid oxidative degradation of the specimen.

A schematic diagram of the rheometer in the parallel plate configuration is shown in Figure 6.

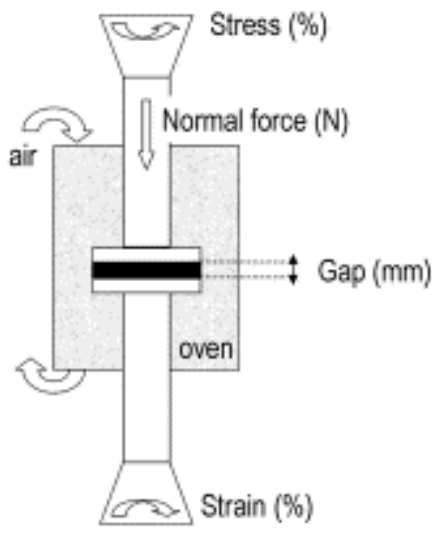

Figure 6 : Schematic of rheometer in the parallel plate configuration

\subsubsection{Solid state nuclear magnetic resonance}

Deoxygenated granular samples were prepared by pumping at high vacuum for $2 \mathrm{~h}$ at $60^{\circ} \mathrm{C}$ in 5-mm o.d. glass tubes and sealing the tubes. Measurements were conducted using a Bruker Avance 400 spectrometer (at Larmor frequency of proton of $400 \mathrm{MHz}$ ). $\mathrm{T}_{1}{ }^{\mathrm{H}}$ recovery curves were then measured with the saturation-recovery sequence with direct proton observation. Three closely spaced $90^{\circ}$ pulses accomplished the saturation.

As a semi empirical approach to analysis, these saturation-recovery curves were fit to a two-exponential equation according to:

$$
M(t)=M_{0 S}\left(1-e\left(-t / T_{1 s}{ }^{H}\right)\right)+M_{01}\left(1-e\left(-t / T_{11}{ }^{H}\right)\right)
$$

where $\mathrm{M}(\mathrm{t})$ is the magnetization at time $\mathrm{t} ; \mathrm{M}_{0 \mathrm{~s}}$ and $\mathrm{M}_{01}$ are the magnetization of the short and long components, respectively, and; $\mathrm{T}_{1 \mathrm{~s}}{ }^{\mathrm{H}}$ and $\mathrm{T}_{11}{ }^{\mathrm{H}}$ are the proton longitudinal relaxation times of the short and long components, respectively.

The equation was fitted with the commercial program TableCurve2D of Jandel Scientific with a standard least-squares minimization (Gaussian elimination). The accuracy of the fit 
was evaluated by an analysis of residuals in a $95 \%$ confidence domain. All fitted values of $\mathrm{T}_{11}{ }^{\mathrm{H}}$ and $\mathrm{T}_{1 \mathrm{~s}}{ }^{\mathrm{H}}$ had 3 and $5 \%$ standard uncertainties, respectively. Corresponding standard uncertainties for the two $\mathrm{M}_{0}$ 's were typically less than $5 \%$.

\section{Results}

\subsubsection{TEM analysis}

TEM pictures of the PA6 nanocomposite are presented on Error! Reference source not

found.. These pictures show that clay platelets are individually and evenly dispersed in the polymeric matrix.
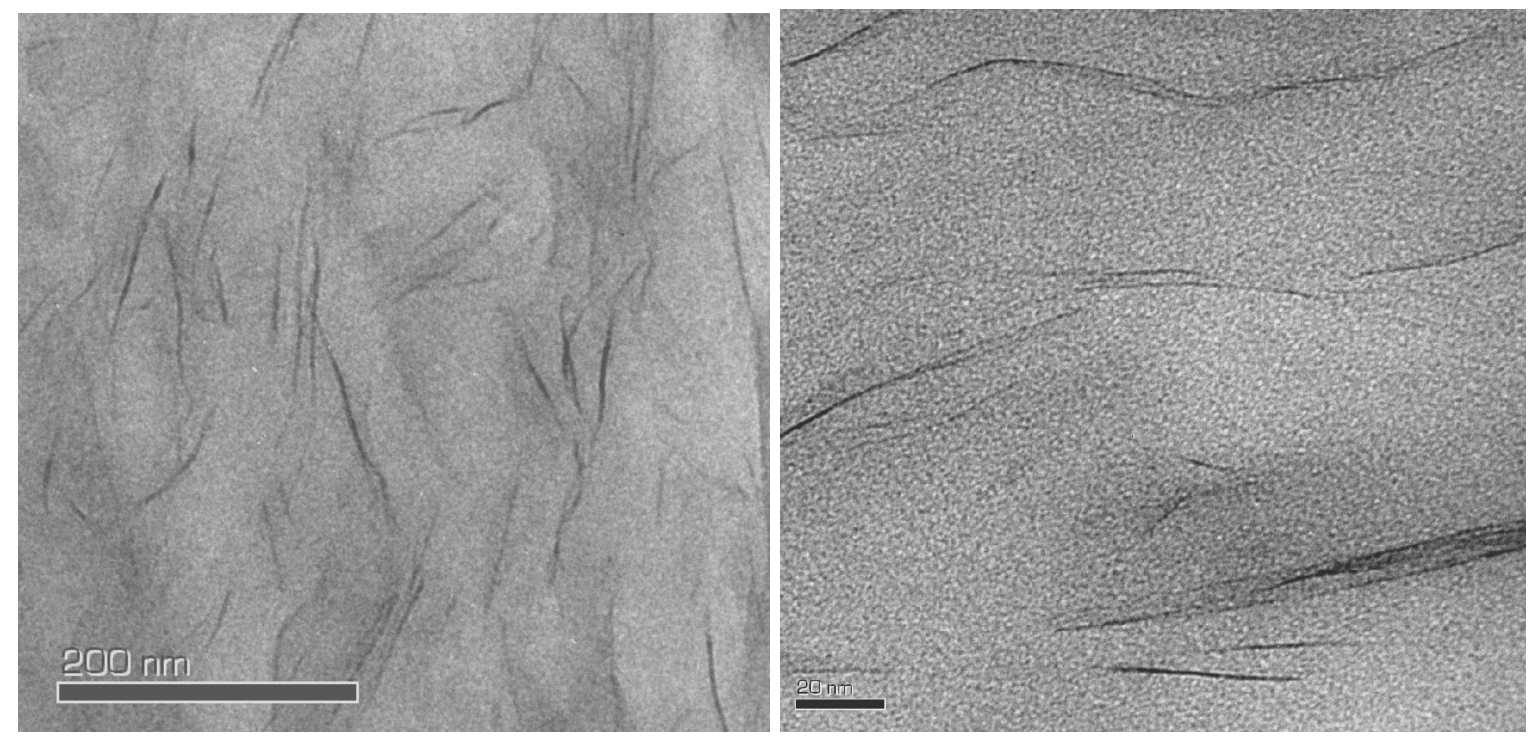

Figure 7 : TEM pictures of the PA6 nanocomposite

The dispersion achieved in the PBT is illustrated by the TEM pictures shown on Error! Reference source not found. Tactoids of 8/10 layers in size can be observed. The distance between the platelets (estimated at $30 \AA$ ) confirms the intercalation suggested by XRD. Objects gathering a limited number of platelets are present in the material with a distance between the platelets which suggests that intercalation occurs. 


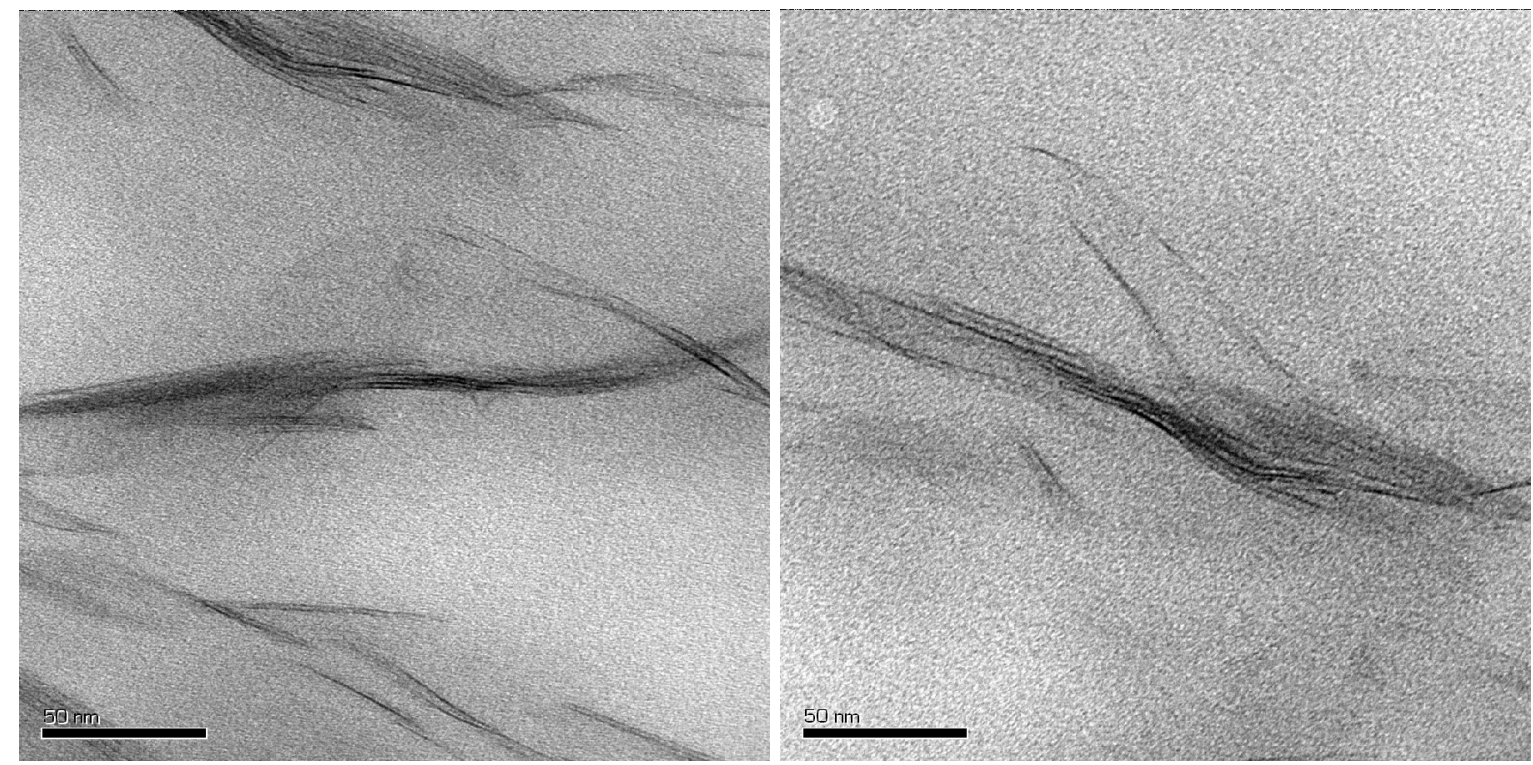

Figure 8 : TEM picture of the PBT nanocomposite

The PP material exhibits a complex structure with a few exfoliated platelets and big tactoids. The platelets in the tactoids only present a slight degree of intercalation.

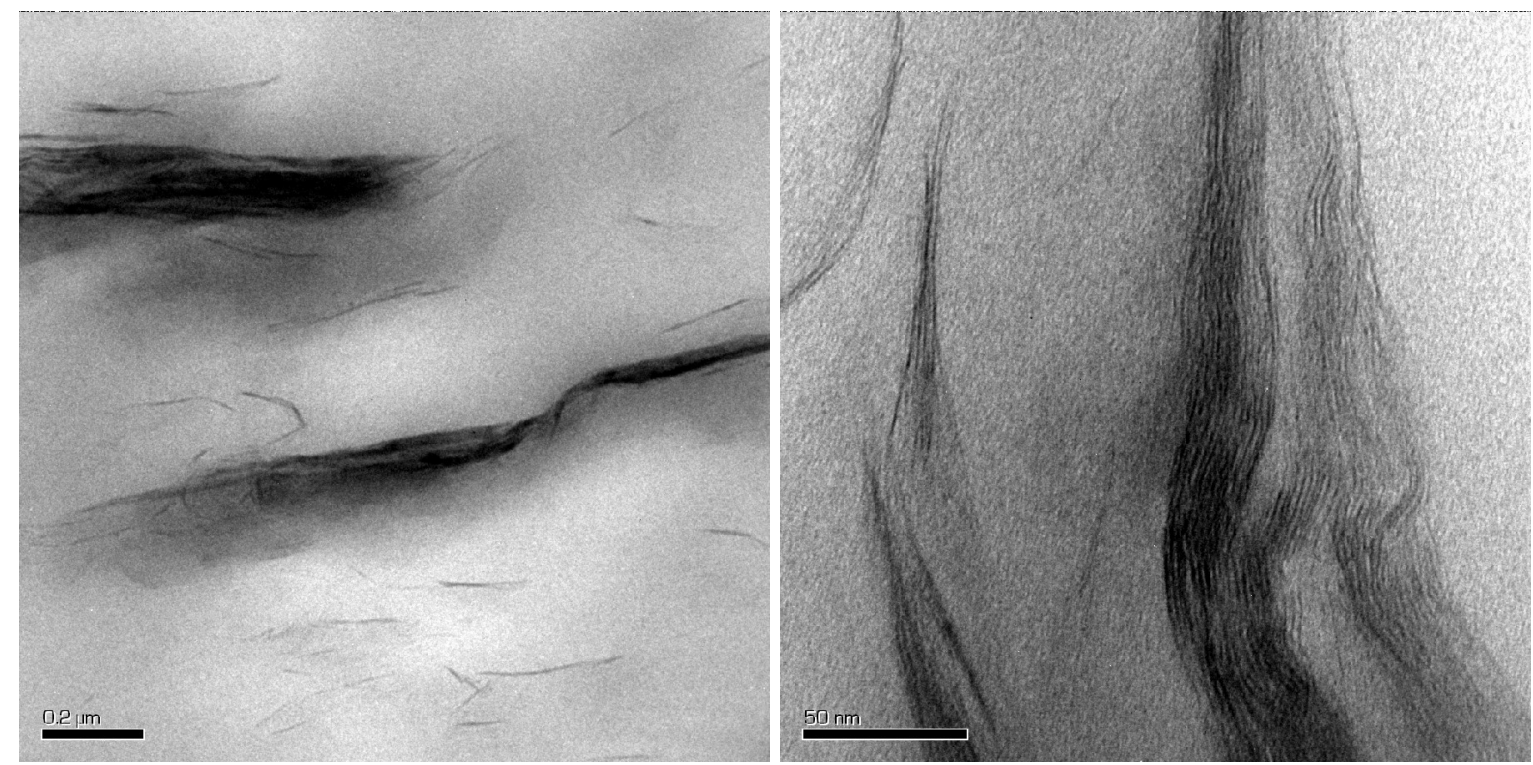

Figure 9 : TEM picture of the PP nanocomposite

\subsubsection{XRD}

Figure 10 presents XRD spectra recorded for the Cloisite 30B and the PA6 nanocomposite. Cloisite $30 \mathrm{~B}$ exhibits a peak at $4.7^{\circ}$ of $2 \theta$ values what corresponds to a d-spacing of $18.8 \AA$ (neat Cloisite $30 \mathrm{~B}$ exhibits a d-spacing of $18.5 \AA$ ). For the prepared nanocomposite no peak is observed. This result suggests exfoliation of the platelets what is confirmed by the TEM picture where delaminated platelets are observed. 


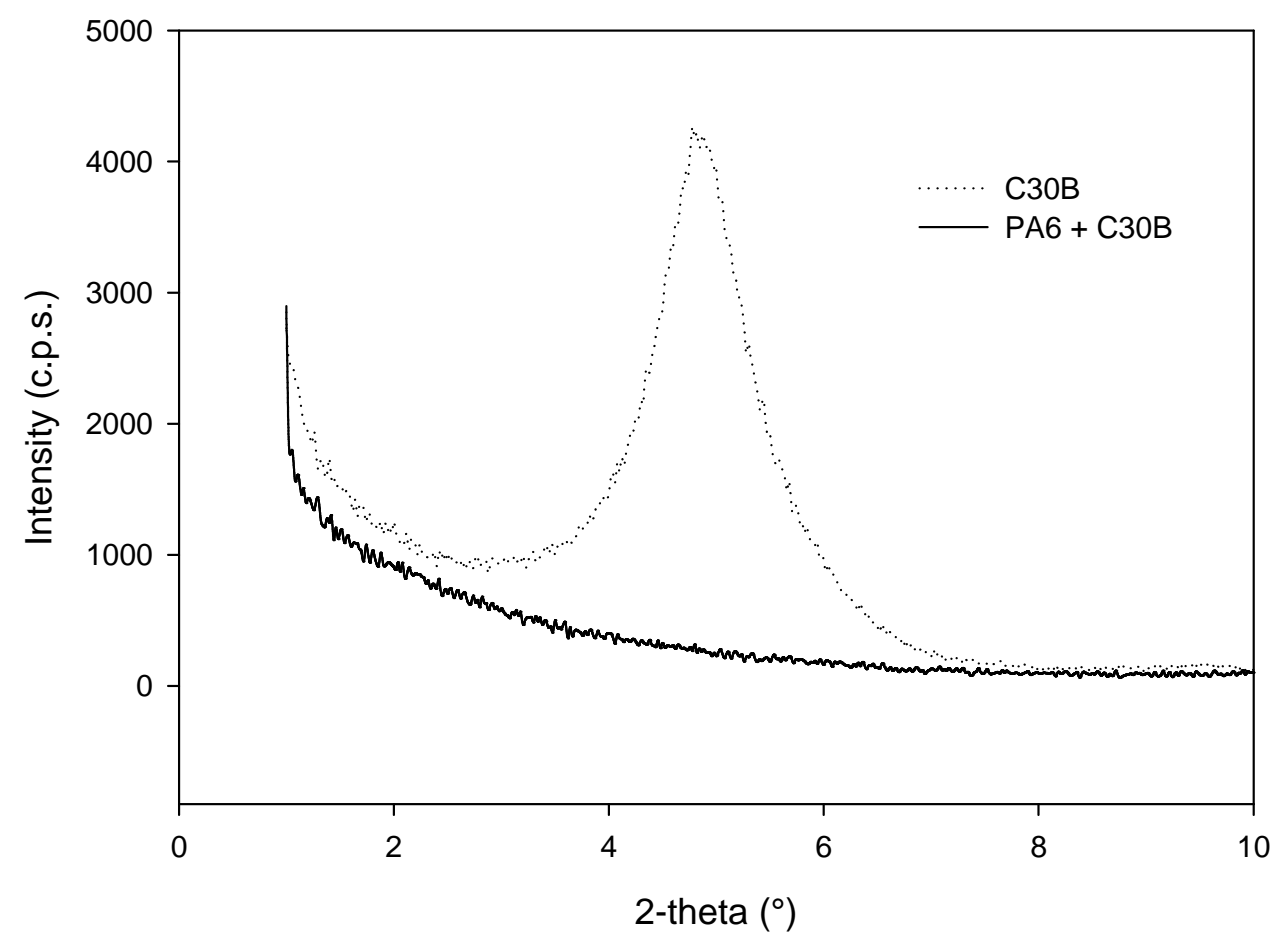

Figure 10: XRD spectra of $\mathrm{C} 30 \mathrm{~B}$ and $\mathrm{PA6} / \mathrm{C30B}$ nanocomposite

XRD analyses have been performed on C30B and a slab of PBT nanocomposite (Figure 11). The signal at $4.7^{\circ} 2$ theta, which corresponds to the d-spacing of Cloisite $30 \mathrm{~B}$, is shifted to $2.2^{\circ}$ 2theta in the case of the nanocomposite, corresponding to an interlayer distance of $40 \AA$. The increase of $21.8 \AA$ in the distance between the platelets could be attributed to the intercalation of polymer chains into the clay galleries. This conclusion is in agreement with the TEM observations. 


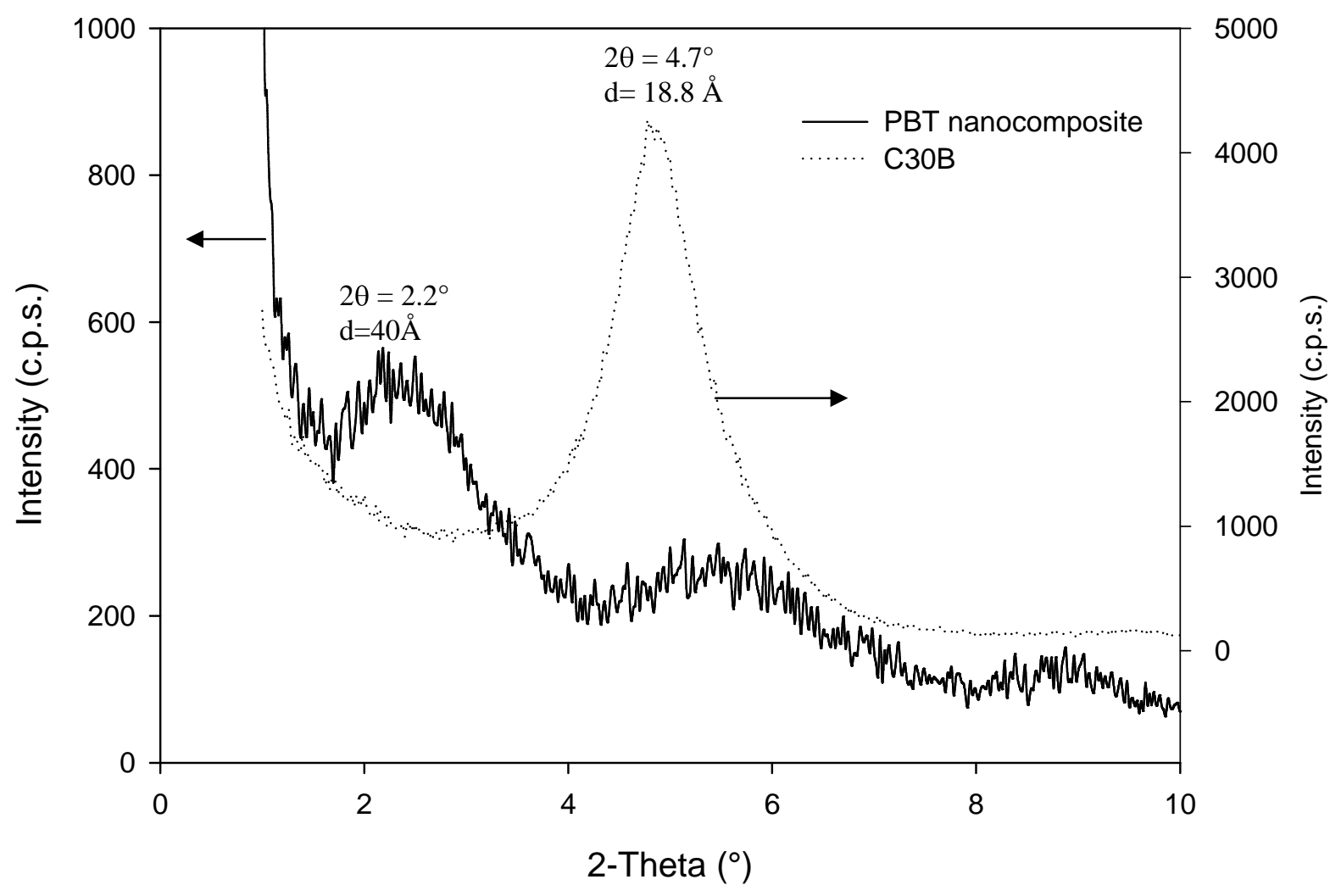

Figure 11 : XRD spectra of C30B and PBT/C30B nanocomposite

Figure 12 presents the XRD analyses of the C20A and the PP nanocomposite. C20A exhibits a peak at $3.6^{\circ}$ of 2 -theta values what means interplatelets distance of $24.5 \AA \quad\left(\mathrm{d}_{001}=24.2 \AA\right.$ according to the data sheet of the supplier). For the PP nanocomposite, a shift from $3.6^{\circ}$ to $3.4^{\circ}$ 2theta of the peak corresponding to the d-spacing of $\mathrm{C} 20 \mathrm{~A}$ is observed, which means an increase of the d-spacing from 24.5 to $25.9 \AA$. According to this result, there is probably not much intercalation of polymer into the galleries This corroborates the poor dispersion shown on the TEM images where big tactoids where observed with only slight intercalation. 


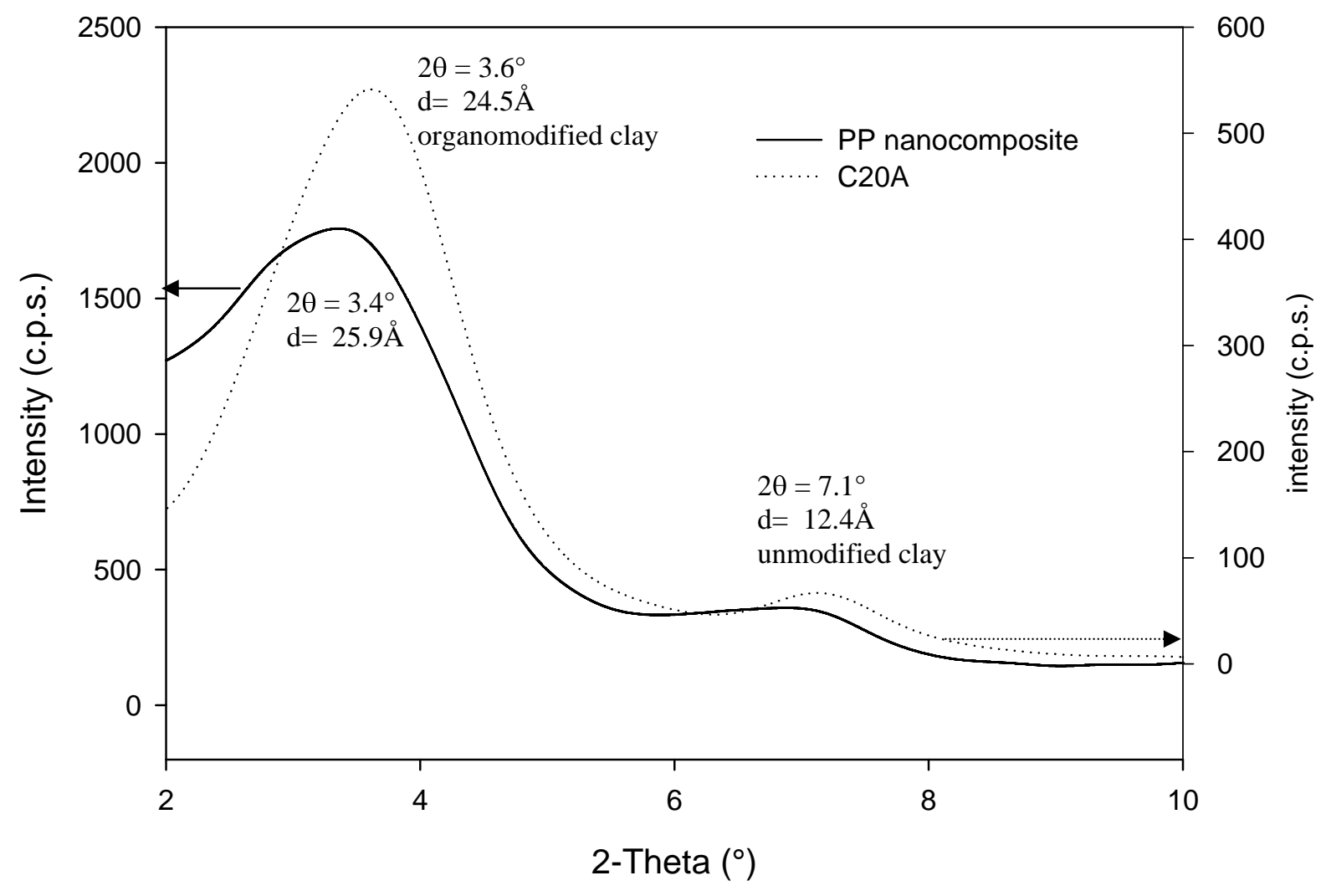

Figure 12: XRD spectra of C20A and PP nanocomposite

\subsubsection{Rheology}

Figure 13 presents the complex viscosity curve of PA6 materials. The steady state viscosity behaviour of neat PA6 shows perfect Newtonian behaviour whereas the absolute value of the melt viscosity of the PA6 nanocomposite sample is significantly higher than that of neat PA6, particularly at low shear rate. This significant increase in zero shear rate viscosity of PA6 nanocomposite indicates that the nanostructure of the nanocomposite consists of percolated network superstructure of exfoliated platelets. The complex viscosity of PA6 nanocomposite sample however, sharply decreases with increasing frequency exhibiting pronounced shear thinning with a shear thinning component $\eta=-0.42$. This marked shear thinning behaviour over whole frequency range investigated suggests higher extent of aluminosilicate exfoliation on nanoscale with a macroscopic preferential orientation of clay layers. 


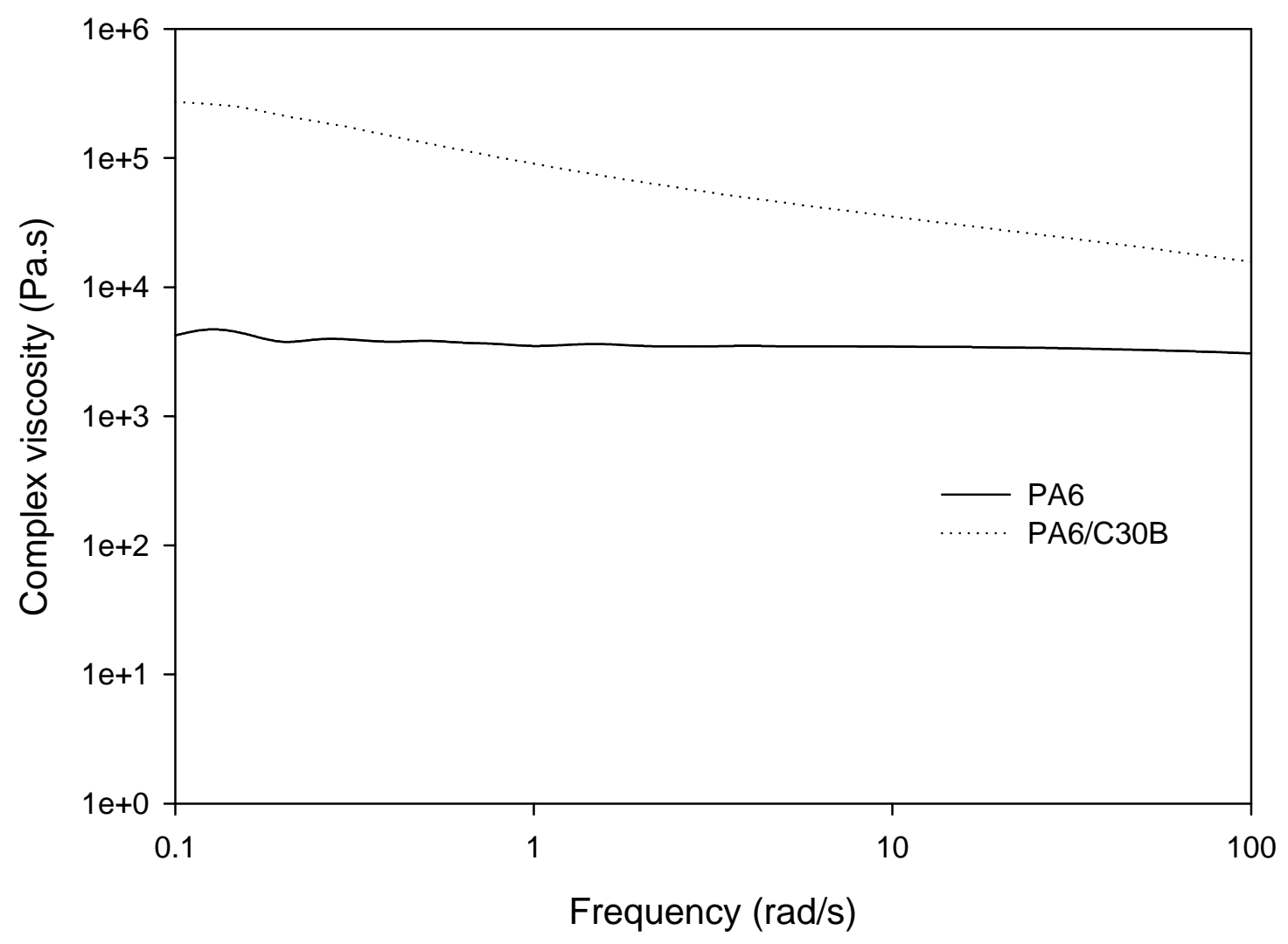

Figure 13 : Complex viscosity curves of PA6 and the nanocomposite versus frequency

Figure 14 shows complex viscosity curves for PBT and the nanocomposite. Neat PBT shows perfect Newtonian behaviour over all the frequency range measured, giving shear thinning exponent $\eta=-0.02$. The nanocomposite sample containing Cloisite 30B shows a nonNewtonian behaviour in the low frequency region and pronounced shear thinning at higher frequencies. The shear thinning component for the nanocomposite is $\eta=-0.67$. Significant increase in zero shear viscosity and pronounced shear thinning at low loading levels of $5 \%$ is a characteristic feature of nanocomposite structure. This has been verified with XRD results which show significant change in d spacing of $21.2 \AA$ and by TEM. 


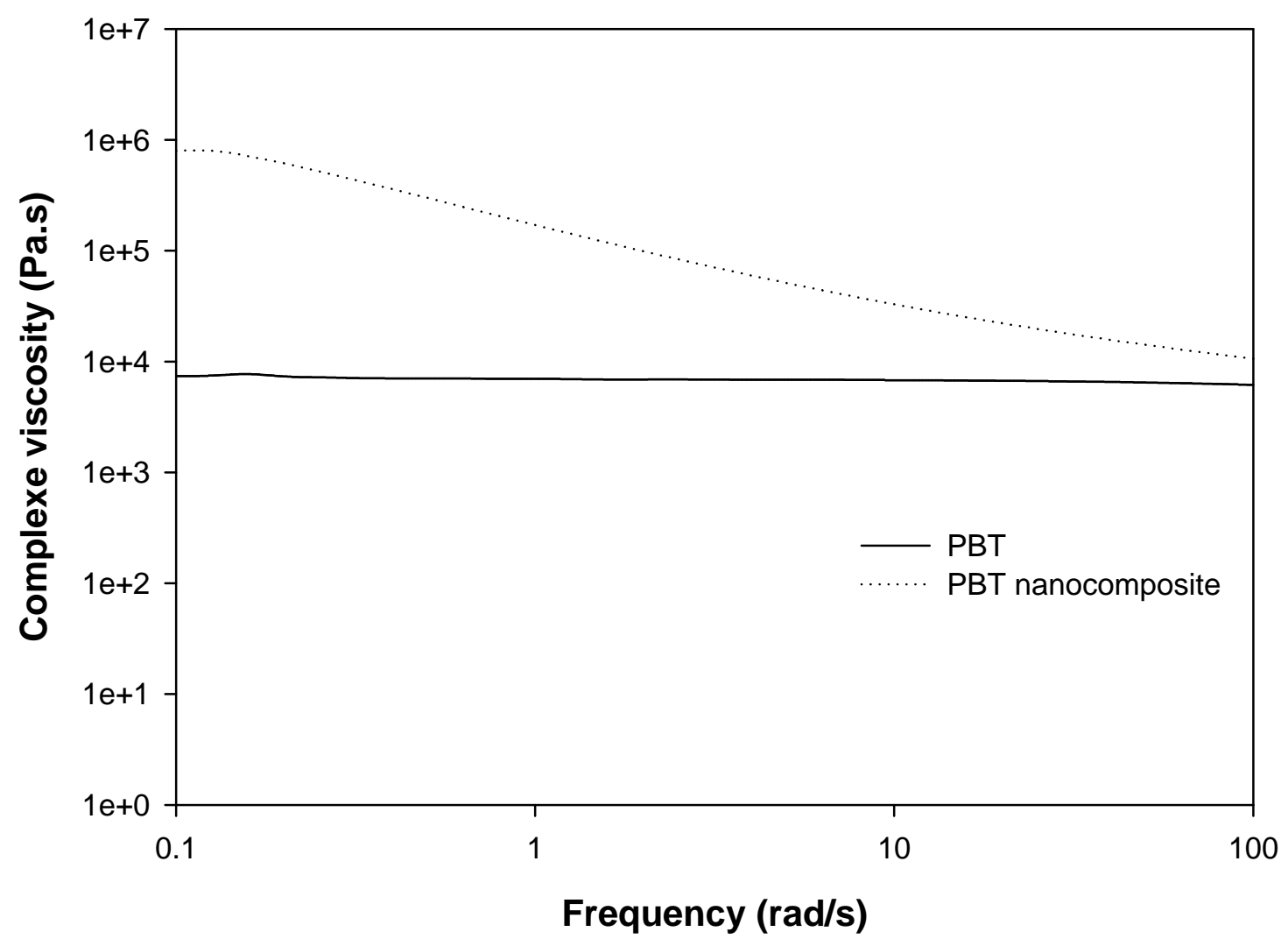

Figure 14: Complex viscosity curves for pure PBT and PBT nanocomposite

Complex viscosity curves obtained from dynamic frequency sweep experiments for PP and the composite are given in Figure 15.

Complex viscosity curve for the PP nanocomposite shows slight increase in viscosity as compared to neat PP over all frequencies measured. However, the complex viscosity curve of the nanocomposite sample does not show any shear thinning. This suggests that the nanoclay forms tactoids with some intercalation of polymeric chains between the platelets. The rheological data for the nanocomposite sample certainly does not show exfoliation or nanodispersion of the nanoclay. This is in agreement with the XRD results with change in $\mathrm{d}$ spacing of $1.4 \AA$ which indicates minor separation of clay platelets but certainly not significant intercalation or exfoliation as expected in nanodispersed polymer-clay hybrid. 


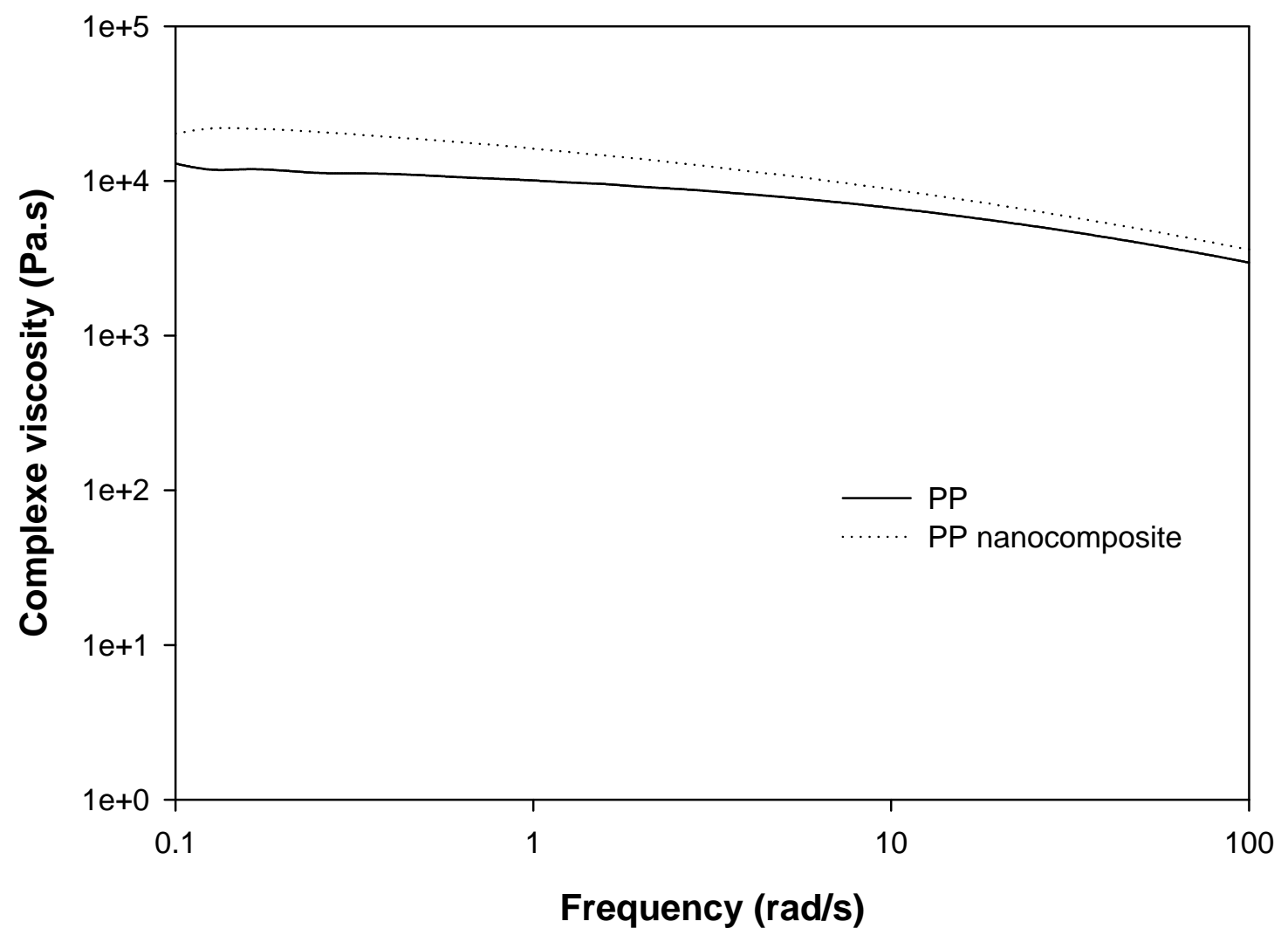

Figure 15: Complex viscosity curves of pure PP and the nanocomposite

\subsubsection{Solid state NMR}

$\mathrm{T}_{1}{ }^{\mathrm{H}}$ values have been measured fitting the experimental data according to the protocol described in the described in the experimental. As an example, Figure 16 presents the saturation recovery curves of both PA6 and PA6/C30B materials. The values are gathered in

Table 5. As expected, the presence of clay shortens the relaxation time in the case of PA6 and PBT nanocomposites because of the paramagnetically induced relaxation at the polymer-clay interface (from $1.67 \mathrm{~s}$ for pure PA6 to $0.77 \mathrm{~s}$ for PA6/C30B and from $2.49 \mathrm{~s}$ for pure PBT to $1.32 \mathrm{~s}$ for PBT/C30B) what indicates that some extent of clay dispersion is achieved. The PP nanocomposite does not present a real decrease of the $\mathrm{T}_{1}{ }^{\mathrm{H}}$ in comparison with the pure PP. 


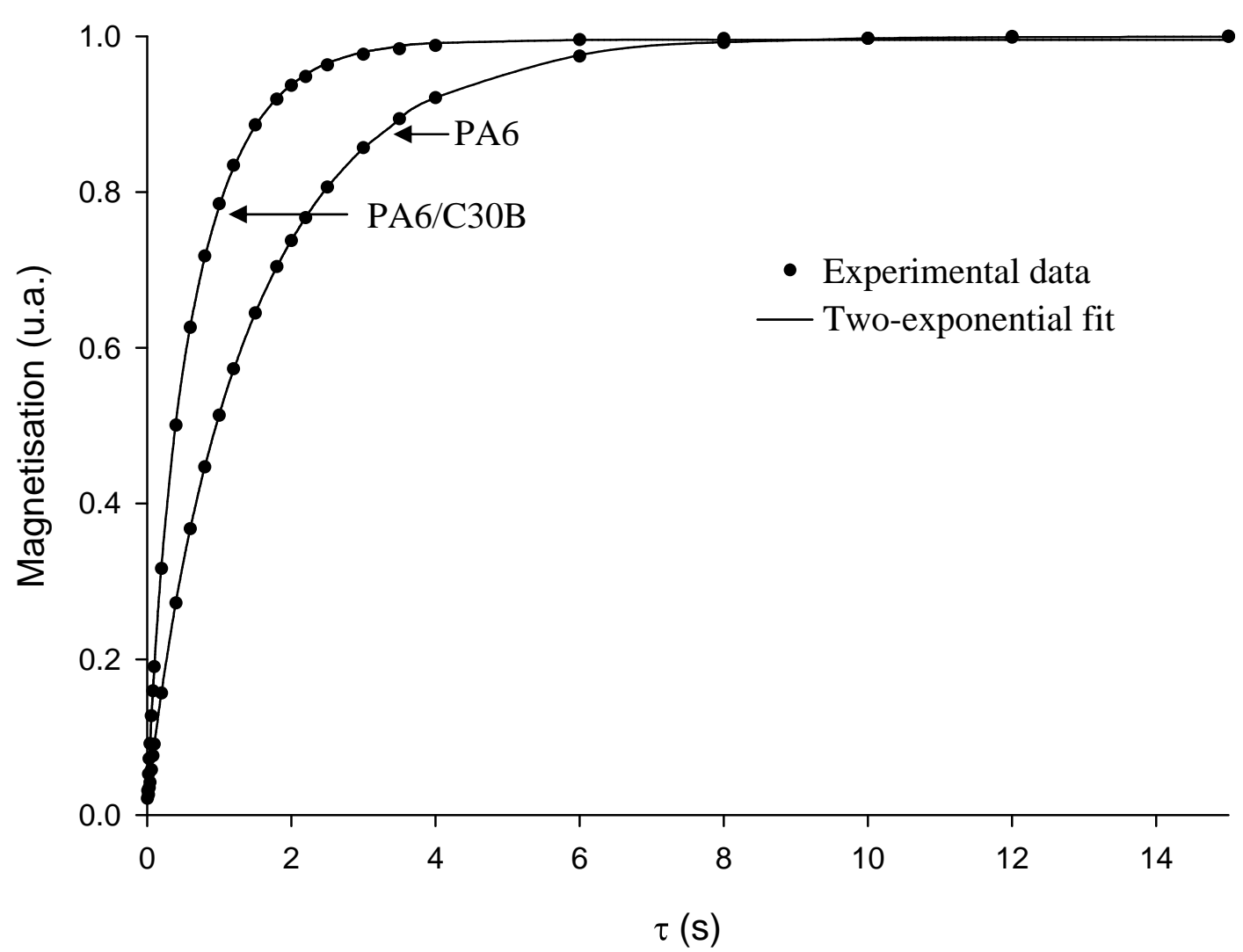

Figure 16: saturation-recovery curves of PA6 and PA6/C30B materials and the two-exponential fit

The spin diffusion model has been applied to obtain a quantitative description of the dispersion.

The first part (at the very earliest times) of the total spin magnetization curve is related to the polymer-clay interfacial area available in the matrix, or in other words, the initial slope of the curve is proportional to the polymer-clay interface concentration. Curves of Figure 17 show that the experimental magnetizations exhibit a reasonably linear dependence vs. the square root of the time $(5 \mathrm{~ms}<t<50 \mathrm{~ms}$ ) for the three nanocomposites 


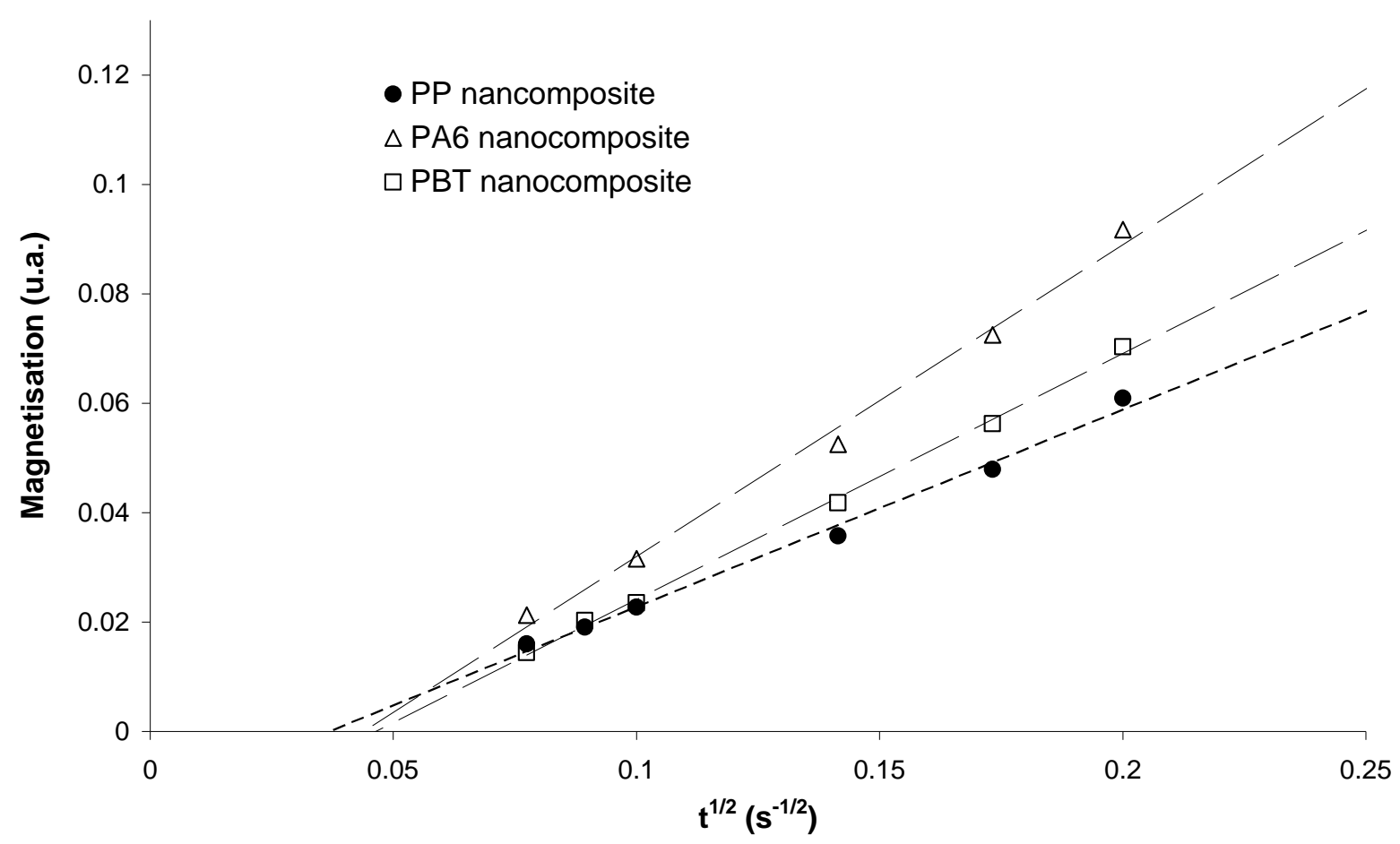

Figure 17: Magnetization from saturation-recovery experiment vs. the square root of the time of deoxygenated PP/C20A, PA6/C30B and PBT/C30B nanocomposites

To calculate the fraction of the effective polymer-clay interfacial area, $f$, from the initial slopes, we need to slopes, we need to choose a reference sample which exhibits a fully exfoliated structure. A PS/MMT PS/MMT nanocomposite has been used as reference where the organo-modifier of MMT was $N, N$ $N, N$-dimethyl-n-hexadecyl-(4-vinylbenzyl) ammonium chloride (VB16) and hereafter called PS/VB16 ${ }^{28}$. PS/VB16 ${ }^{28}$. The important parameter obtained from the reference sample is $\left(T_{1}{ }^{\mathrm{H}}\right)_{\mathrm{S}}$, which was determined determined to be $2.5 \mathrm{~ms}$ at $400 \mathrm{MHz}$. We also stated that $T_{11}{ }^{\mathrm{H}}$ is a relative indicator of the homogeneity of homogeneity of the distribution of the actual polymer-clay interfaces in the nanocomposite. We can We can compute, using our model calculation, an apparent spacing, $\Delta_{\text {app }}$ that matches the $T_{11}{ }^{\mathrm{H}}$ obtained obtained from the experimental curves. We can then compare $\Delta_{\text {app }}$ with $\Delta_{f}$, the spacing in an ideally ideally layered structure that has a surface area $f$ times the amount expected from full exfoliation. Thus, exfoliation. Thus, we define a parameter, $e=\Delta_{f} / \Delta_{\text {app }}$, to be a qualitative monitor of the inhomogeneity of the inhomogeneity of the distribution of clay where poor homogeneity would correspond to $e \& 1$ and good and good homogeneity would yield $e=1$. The values of $f$ and $e$ are presented in

Table 5. 
Table 5 : NMR parameters for the characterization of the dispersion

\begin{tabular}{|c|c|c|c|}
\hline Materials & $\mathrm{T}_{1}{ }^{\mathrm{H}}$ & $\mathrm{f}$ & $\mathrm{e}(\%)$ \\
\hline PA6 & 1.67 & & \\
\hline PA6 + NC & 0.77 & 0.81 & 98 \\
\hline PBT & 2.49 & & \\
\hline PBT + C30B & 1.32 & 0.50 & 67 \\
\hline PP & 0.97 & & \\
\hline PP + C20A & 0.94 & 0.10 & 44 \\
\hline
\end{tabular}

According to these results, three kinds of morphologies are obtained depending on the polymer used. C30B is well dispersed into the PA6 matrix: the platelets are well separated and the dispersion of the platelets is clearly achieved. A nanocomposite has been obtained and the morphology is exfoliated. The material prepared by incorporation of C30B in a PBT matrix presents an intermediate dispersion. The $\mathrm{f}$ value of 0.50 indicates the presence of intercalation and/or small tactoids in the material. These tactoids are quite well homogeneously dispersed in the matrix according to the e of $67 \%$. The nanodispersion of the clay in PP matrix is not achieved. The low $\mathrm{f}$ value suggests that big tactoids are included in the materials and the value of e near $50 \%$ shows that the homogeneity of the dispersion of the tactoids is medium.

\section{Discussion}

Three composites based on polymers and nanoclays have been prepared by melt blending and then analysed by XRD, melt rheology and NMR measurements and TEM. Different levels of dispersion have been achieved and confirm unambiguously by the four techniques.

The dispersion of Cloisite 30B in the nanocomposite based on PA6 has been fully investigated. The X-Ray diffraction analysis has highlighted the disappearance of the lamellar structure of the clay leading to the assumption that an exfoliated morphology was probably achieved. Then the use of melt rheology has confirmed this result. Shear thinning, especially at low frequencies is observed revealing a pronounced intercalation of the clay. NMR measurements are in agreement with the two previous analyses but as a bonus quantified the 
nanodispersion via its two parameters $\mathrm{f}$ and $\varepsilon$. A shortened spin lattice relaxation time is measured in presence of clay. The quantification indicates homogeneity of the repartition of the clay of $98 \%$ and a very high level of platelets separation. The TEM pictures taken for this sample show the exfoliation of the clay.

Concerning the nanocomposite based on PBT and C30B, the three analyses are consistent with the conclusion that an intercalated morphology is obtained. The d-spacing is increased of 21.2 $\AA$, shear thinning is observed. This is confirmed by the NMR results and TEM pictures.

Eventually, for the materials based on polypropylene, the three techniques show that the nanodispersion of the clay is not achieved even if a compatibilizer (polybond) was used. A slight increase of $\mathrm{d}$-spacing is recorded (only $1.4^{\circ}$ ). The melt rheology properties of the materials are not those expected for a nanocomposite (no shear thinning). Finally the NMR measurements and TEM clearly confirm the poor dispersion.

Moreover this study expands the application field of the NMR method to define the morphology of nanocomposites to two other polymeric matrices (PP and PBT) and the confrontation with the other tests validates unambiguously the results.

\section{Conclusion}

Overview of the literature and investigation of the methods to characterize the dispersion in polymer nanocomposites done in this work permit us to make recommendations to completely investigate the nanodispersion. . Their advantages and weaknesses have been reminded and experimentally tested on three nanocomposites. TEM has been used to qualitatively characterise the dispersion. It is a very effective method for such analysis and it can even be quantitative thanks to image analyses but its major drawback lies in the scale of the analysis. A picture is not representative of the whole sample and many pictures have to be analysed to mirror the global repartition of the clay. So it remains a very time consuming method. XRD is particularly adapted to the study of intercalated morphology of nanocomposite since the distance between two platelets can be calculated. The limitation of this technique appears when no peak is detected. In this case no direct conclusion can be done and the result has to be confirmed using a second characterising method. Melt rheology and solid state NMR are bulk analyses. During the measurement the sample is representative of the material. Rheology appears to be simple to realize and the results are rapidly obtained. Moreover a classification of the sample according to the dispersion state can be established. NMR is also a quite rapid and easy method and overall it is quantitative measurements. 


\section{Acknowledgments}

This study was carried out in the frame of the STREP European project "PREDFIRENANO" $N^{\circ} 013998$, in the $6^{\text {th }}$ Framework Program.

\footnotetext{
${ }^{1}$ Y. Kojima, A. Usuki, M. Kawasumi, A. Okada, T. Kurauchi, O. Kamigaito, J. Polym. Sci Part A: Polym. Chem. 31 (1993) 1755-1758

${ }^{2}$ L.M. Liu, Z.N. Qi, X.G. Zhu, J. Appl. Polym. Sci. 71 (1999) 1133-1138.

${ }^{3}$ Z. Wang, T.J Pinnavaia, Chem Mater 10 (1998) 3769-3771

${ }^{4}$ L. Lui, Z. Qi, X. Zhu, J. Appl Polym Sci 71 (1999) 1133-1138

${ }^{5}$ P.B. Messesmith, E.P. Giannelis, J Polym Sci A 33 (1995) 1047-1057

${ }^{6}$ K. Yano, A. Usuki, A. Okada, T. Kurauchi, O. Kamigaito, J Polym Sci A 31 (1993) 2493-2498

7 A. Blumstein, J Polym Sci A 3 (1965) 2665-2673

${ }^{8}$ J.W. Gilman, C.L. Jackson, A.B. Morgan, R. Harris, E. Manias, E.P. Giannelis, M. Wuthenow, D. Hilton, S.H. Phillips, Chem Mater 12 (2000) 1866-1873

${ }^{9}$ J.W. Gilman, Appl Clay Sci 15 (1999) 31-49

${ }^{10}$ H.R. Dennis, D.I. Hunter, D. Chang, S. Kim, J.L. White, J.W. Cho, D.R. Paul, Polymer 42 (2001) 9513-9522

${ }^{11}$ T.D. Fornes, P.J. Yoon, D.L. Hunter, H. Keskkula, D.R. Paul, Polymer 43 (2002) 5915-5933

12 T.D. Fornes, P.J. Yoon, H. Keskkula, D.R. Paul, Polymer 43 (2001) 9929-9940

${ }^{13}$ A. Vermogen, K. Masenelli-Varlot, R. Seguela, J. Duchet-Rumeau, S. Boucard, P. Prele, Macromolecules, 38 (2005) 9661-9669

${ }^{14}$ A. Ranade, N.A. D'Souza and B. Gnade, Polymer 43 (2002) 3759-3766

${ }^{15}$ R.A. Vaia and W. Liu, J Polym Sci, Polym Phys Ed 40 (2002) 1590-1600

${ }^{16}$ S.S. Ray and M. Okamoto, Macromol Rapid Commun 24 (2003) 815-840

${ }^{17}$ D.F. Eckel, M.P. Balogh, P.D. Fasulo and W.R. Rodgers, J Appl Polym Sci 93 (2004) 1110-1117

${ }^{18}$ A.B. Morgan and J.W. Gilman, J Appl Polym Sci 87 (2003) 1329-1338

${ }^{19}$ TJ Pinnavaia, Beall GW, editors. Polymer-Clay Nanocomposites. New York: Wiley; 2000

${ }^{20}$ R . Krishnamoorti, J. Ren, A.S. Silva. J Chem Phys 114 (2001) 4968-73

${ }^{21}$ G. Galgali, C Ramesh, A. Lele, Macromolecules 34 (2001) 8084-93

${ }^{22}$ L Incarnato, P. Scarfato, L. Scatteia, D. Acierno, Polymer 45 (2004) 3487-3496

${ }^{23}$ R Wagener, TJG Reisinger, Polymer 44 (2003) 7513-7518

${ }^{24}$ D.L. VanderHart, A. Asano, J.W. Gilman, Chem Mater, 13 (2001) 3781-3795

${ }^{25}$ D.L. VanderHart, A. Asano, J.W. Gilman, Chem Mater, 13 (2001) 3796-3809

${ }^{26}$ S. Bourbigot, D. L. Vanderhart, J. W. Gilman, W.H. Awad, R.D. Davis, A.B. Morgan, C.A. Wilkie, Journal of polymer science : part B : polymer physics, 41 (2003) 3188-3213

${ }^{27}$ M. Yoonessi, H. Toghiani, T.L. Daulton, J.S. Lin, C.U. Jr. Pittman, Macromolecules, 38 (2005), 818-831

${ }^{28}$ J. Zhu, A. B. Morgan, F. J. Lamelas, C. A. Wilkie, Chem Mater, 13 (2001) 3774-3780
} 